\title{
Evaluation of Patients' Rights Observance According to Patients' Rights Charter in Educational Hospitals Affiliated to Mashhad University of Medical Sciences: Medical Staffs' Views
}

\author{
Alireza Sabzevari ${ }^{1}$, Mohammad Ali Kiani ${ }^{1}$, Masumeh Saeidi ${ }^{2}$, Seyed Ali Jafari ${ }^{1}$, Hamidreza Kianifar ${ }^{1}$, Hamid \\ Ahanchian $^{1}$, Lida Jarahi ${ }^{1}$, Mohsen Zakerian ${ }^{2}$
}

${ }^{1}$ Faculty of Medicine, Mashhad University of Medical Sciences, Mashhad, Iran

${ }^{2}$ Student Research Committee, Faculty of Medicine, Mashhad University of Medical Sciences, Mashhad, Iran

\section{Type of article: Original}

\begin{abstract}
Introduction: To supply quality services and healthcare, it is evident that medical ethics and patients' rights, while providing medical and healthcare services need to be observed. This study was conducted to evaluate observance of the Patients' Rights Charter among medical staff of educational hospitals affiliated to Mashhad University of Medical Sciences.

Methods: This cross-sectional study was conducted in four educational hospitals in Mashhad on eighty physicians, nurses, nurse aids and medical students. Data were collected using a two-part inventory of patients' rights, including demographic data and inventory of patients' rights observance. Data analysis was conducted using SPSS-16 as well as descriptive statistics, independent t-test, chi-square, Spearman correlation coefficient and Pearson correlation.

Results: Mean age of subjects was $36.3 \pm 8.3$. Observance of human rights was perfect by 84.4 percent of subjects. The highest amount of observance of patients' rights was related to the area of respecting patients' privacy and observing the principle of confidentiality, which was evaluated to be perfect by all subjects $(100 \%)$. The lowest value of patients' rights observance was related to presenting appropriate and adequate information for patients, which was perfect among $48.1 \%$ of subjects. There was no significant relation between personal details (age, gender, education and career) and observance of patients' rights ( $\mathrm{p}>0.05)$.

Conclusion: Although in this study, the observance of patients' rights by medical staff is optimal in most areas, the area of providing appropriate and adequate information needs to be promoted. Therefore, it is suggested that more stringent regulatory policies be compiled and implemented to the items of Patients' Rights Charter along with training courses, to strengthen medical staff's awareness in this regard.
\end{abstract}

Keywords: Patients' Rights Charter; Patient Rights; Physicians' Nurses; Medical Students

\section{Introduction}

The Patients' Rights Charter refers to defending human rights to maintain patients' respect and dignity, to ensure that they will be adequately treated physically, especially in emergencies, without any age or gender discrimination or financial incentive, and this care will be provided in an environment replete with high quality and respect (1). The announcement of patients' rights was first published by the National Union of Nurses in 1948 in response to patients' expectations, legal principles of informed consent, confidentiality of information, observance of patients' respect and dignity and admission without discrimination (2). Therefore, rules and regulations were compiled under the title of Patients' Rights Charter, the aim of which, was to defend the rights of patients and to provide the required background for patients to benefit from human dignity and respect in all stages of their experience with medical centers and to ensure lack of discrimination in adequate care for patients in an environment replete with optimal quality (3). Observing this charter by nurses, physicians and other healthcare providers will promote patient care, increase patient satisfaction and will result in efficiency of the health system (4). Studies and experience have shown

\section{Corresponding author:}

Associate Professor Dr. Mahammad Ali Kiani, Faculty of Medicine, Mashhad University of Medical Sciences, Mashhad, Iran. Tel: +98.38412069, Fax:+98.38410137, Email: Kianima@mums.ac.ir

Received: March 21, 2016, Accepted: July 19, 2016, Published: October 2016

iThenticate screening: July 20, 2016, English editing: August 17, 2016, Quality control: September 08, 2016

(C) 2016 The Authors. This is an open access article under the terms of the Creative Commons Attribution-NonCommercialNoDerivs License, which permits use and distribution in any medium, provided the original work is properly cited, the use is non-commercial and no modifications or adaptations are made. 
that informing patients, and their participation in making decisions for treatment and respecting their rights, will accelerate their remission and reduce patients' stay in hospital (5). Needless to say, patients' rights along with their satisfaction of health services are the most important themes of clinical governance (6). According to the definition of the American Health Association, by considering patients' rights, we mean observing their legal and logical physical, mental, spiritual and social needs that are compiled as standard medical rules and regulations and the medical team are responsible and obliged to implement and observe them (7). In Iran, Patients' Rights Charter was compiled in 2002 and it was informed by Health Deputy of the Ministry of Health for Iran in 2003. Main themes of the Patients' Rights Charter are to:

1) Receive optimal health services, which is the patient's right.

2) Give information to patients adequately and optimally.

3) Respect freedom of choice and patients' decision-making in receiving health services.

4) Provide health services based on respecting patients' privacy and observing the principle of confidentiality.

5) Have the right to access an efficient system of handling complaints $(6,7)$.

Although compiling and informing a patients' rights charter is a valuable measure to fulfill patient's rights, various studies show various degrees of observing patients' rights in medical centers, as such, that some evidence suggests observing legal and ethical aspects by medical staff to be lower than average or not optimal (8). Results of previous studies, suggest the lack of physicians, nurses and hospital administrators' knowledge of patients' rights and lack of full observance of these rights in hospitals under study. Results of a study show that observance of patients' rights by physicians has been poor despite their full knowledge (9). In addition, the knowledge related to medical ethics among medical students, interns and residents of surgery in surgery wards has been very poor (8). In another study, observance of patients' rights by nurses has been average in more than half of cases (12). In similar studies on observance of Patients' Rights Charter issued in 2002, Vaskooei Eshkevari et al. reported its observance in hospitals of Tehran University of Medical Sciences to be 53\% (13). Rangraz Jeddi reported its observance to be $67.7 \%$ in state hospitals of Kashan (14) and Malek Shahi reported it to be 56.2\% in Shohada Hospital of Khorram Abad (15). Obviously, there are studies where in some private clinics affiliated to healthcare system of Shahr-e Rey, most provisions of patients' rights charter are observed. However, in other cases that entail lack of patients' knowledge of medicine, complications, unfamiliarity with the name and position of service providers, lack of knowledge about referral process, and lack of knowledge of medical services' tariffs are not fully observed (15) and this, while the patients' rights charter is not being observed, can endanger patients' health, life and security and it can undermine the relationship between medical and health staff which will finally result in reduced efficiency of services and patient care (16). As one of the main pillars of providing health services, hospitals should create a background of understanding and respect patients' rights (17). Being informed of the views of medical and care staff about the Patients' Rights Charter can create the background to observe those rights more efficiently. Therefore, considering the importance of this issue and lack of adequate studies on patients' rights, particularly according to physicians and nurses working at Mashhad University of Medical Sciences, this study was conducted to investigate the observance of patients' rights by medical staff (physicians, nurse aids, medical students and nurses) working at educational hospitals in Mashhad.

\section{Material and Methods}

\subsection{Research design}

This was a descriptive cross-sectional study. The study sample included eighty physicians, nurses, nurse aids and medical students studying at four educational hospitals affiliated to Mashhad University of Medical Sciences.

\subsection{Inclusion Criteria}

Inclusion criteria comprised of one year of work experience in intended educational hospitals and having written and informed content. Exclusion criteria included being unwilling to continue participating in the study, failing to complete over $30 \%$ of questions in inventory, and work experience of less than a year. In this study, all physicians, nurse aids, nurses and students, who were working at internal and surgical wards of educational hospitals of Mashhad University of Medical Sciences with inclusion criteria, filled the inventory.

\subsection{Instrument and data collection}

Research inventory composed of two parts: 1) Demographic data (14 questions); and 2) The inventory of observance of patients' rights based on the chart developed by the Ministry of Health and Medical Education, including 41 questions. In this study, the inventory of awareness of patients' rights was calculated and reported in 41 questions with "No and Never=0" and "Yes=1" responses by calculating an average of total scores (range from zero to 41) and to facilitate understanding and interpreting results based on 100 (score 100) (Table 1). In terms of areas of the 
inventory, the range of changes in each area was divided into four sections of low to excellent. This means that a quarter down the range of each area was in low range, between a quarter to half, it was average, between half and three-quarters it was good and over three-quarters, it was classified as excellent. In this study, formal validity of the inventory was verified by seven experts and its reliability, using Cronbach's alpha, was 0.84 .

Table1. The level of knowledge and patient rights by medical staff in teaching hospitals of Mashhad city

\begin{tabular}{|l|l|}
\hline Average scores & The knowledge and rights of the patient in the hospital \\
\hline Excellent & $>86$ \\
\hline Good & $76-85$ \\
\hline Average & $51-75$ \\
\hline Low & $25-50$ \\
\hline Very low & $<25$ \\
\hline
\end{tabular}

\subsection{Data analysis}

Data analysis was conducted using SPSS-16 (SPSS Inc., Chicago, Illinois, USA) at significance level of $p<0.05$, such that to study the relation of personal details of subjects with the main variable (amount of observing patients' rights by medical staff), first the normal distribution of quantitative variable was verified by Kolmogorov-Smirnov and Shapiro tests. Then, to investigate the relation of background variables with the main variable, independent ttest, chi-square, and Pearson and Spearman correlation coefficient were employed.

\section{Results}

Subjects of this study were eighty medical staffs (physicians, nurse, nurse aid, and medical students) working at internal and surgical wards of educational hospitals affiliated to Mashhad University of Medical Sciences who were studied in 2015. Mean age of subjects was 36.3 \pm 8.3 (range: $22-55$ years). The population consisted of $50 \%$ males and $50 \%$ females. In terms of education, $36.2 \%$ of subjects were Bachelors and $25 \%$ were $\mathrm{PhD}$. In terms of career, $37.5 \%$ of subjects were nurses and $25 \%$ were physicians.

\subsection{Observance of Patients' Rights Based on Items of the Inventory}

Findings showed that knowledge of most of the subjects under study regarding items of patients' rights, inventory was optimal, and $100 \%$ of them were informed about components of observing patients' rights. The lowest rates of observing patients' rights were related to the lack of being informed of treatment details and immediate optimal care, patients' decision-making on clinical presence of those who did not directly participate in the patients' treatment and being aware of the fact that the patient can ask to be respected as a human being were not observed by $100 \%$ of subjects at it was common among four groups of physicians, nurses, nurse aids and medical students. Chi-square test showed that there was no significant difference between items of inventory among physicians, nurses, nurse aids, and medical students $(\mathrm{p}>0.05)$.

3.1.1. Observance of patients' rights by physicians

Patients' rights were observed in most items by most physicians; however, their lowest knowledge was respectively related to the extent of state insurance coverage, complementary programs and referral systems to health services and social facilities (94.4\%), being aware of patients' round-the-clock access to their lawyers $(85 \%)$ and patients' participation in selecting the final treatment method (50\%).

3.1.2. Observance of patients' rights by nurses

Patients' rights were observed in most items by most nurses; however, the lowest rate of observance of patients' rights was related to being aware of patients' round-the-clock access to their lawyers (76.7\%), patients' participation in selecting the final treatment method (63.3\%) and request to investigate and read the file $(50 \%)$.

3.1.3. Observance of patients' rights by nurse aids

Patients' rights were observed in most items by most nurse aids; however, the lowest rate of observance of patients' rights was related to patients' participation in selecting the final treatment method $(66.7 \%)$, the right to receive essential information on possible complications or use of other methods before examinations (20\%) and patients' confidence of the fact that they will not be treated without informed consent $(13.3 \%)$.

3.1.4. Observance of patients' rights by medical students

Patients' rights were observed in most items by most medical students; however, the lowest rate of observance of patients' rights was related to being aware of patients' round-the-clock access to their lawyers (73.3\%), patients' participation in selecting the final treatment method $(53.3 \%)$ and the right to receive essential information on possible complications or use of other methods before examinations $(100 \%)$. 


\subsection{Observance of Patients' Rights based on the Areas of Patients' Rights Charter}

\subsubsection{Receiving optimal health care}

Mean rate of optimal health services received in subjects was 89.9 5 5.6 (out of 100) (range: 77.8-100). In addition, optimal health services received was excellent in $91.2 \%$ of subjects. Results of chi-square showed no significant difference among four groups in terms of this area (Table 1).

Table 2. The patients' rights on the basis of the four areas from the perspective of medical staff

\begin{tabular}{|c|c|c|c|c|c|}
\hline \multicolumn{2}{|l|}{ Variables } & Status & $\mathrm{n}$ & $\%$ & p-value \\
\hline \multirow{11}{*}{ Area of receiving optimal health care } & \multirow[t]{3}{*}{ Physician } & Good & 2 & 10 & \multirow{11}{*}{0.503} \\
\hline & & Excellent & 18 & 90 & \\
\hline & & Total & 20 & 100 & \\
\hline & \multirow[t]{3}{*}{ Nurse } & Good & 4 & 13.3 & \\
\hline & & Excellent & 26 & 86.7 & \\
\hline & & Total & 30 & 100 & \\
\hline & \multirow[t]{2}{*}{ Nurse aid } & Excellent & 15 & 100 & \\
\hline & & Total & 15 & 100 & \\
\hline & \multirow[t]{3}{*}{ Medical student } & Good & 1 & 6.7 & \\
\hline & & Excellent & 14 & 93.3 & \\
\hline & & Total & 15 & 100 & \\
\hline \multirow{14}{*}{$\begin{array}{l}\text { Area of providing appropriate and adequate } \\
\text { information to patients }\end{array}$} & \multirow[t]{4}{*}{ Physician } & Average & 1 & 5.6 & \multirow[t]{12}{*}{0.099} \\
\hline & & Good & 8 & 44.4 & \\
\hline & & Excellent & 9 & 50 & \\
\hline & & Total & 18 & 100 & \\
\hline & \multirow[t]{4}{*}{ Nurse } & Average & 6 & 20 & \\
\hline & & Good & 14 & 46.7 & \\
\hline & & Excellent & 10 & 33.3 & \\
\hline & & Total & 30 & 100 & \\
\hline & \multirow[t]{3}{*}{ Nurse aid } & Good & 4 & 28.6 & \\
\hline & & Excellent & 10 & 71.4 & \\
\hline & & Total & 14 & 100 & \\
\hline & \multirow{3}{*}{ Medical student } & Good & 7 & 46.7 & \\
\hline & & Excellent & 8 & 53.3 & \\
\hline & & Total & 15 & 100 & \\
\hline \multirow{12}{*}{$\begin{array}{l}\text { Area of respecting the patient's right to choose and } \\
\text { decide freely to receive health services }\end{array}$} & \multirow{3}{*}{ Physician } & Average & 3 & 15 & \multirow[t]{12}{*}{0.791} \\
\hline & & Excellent & 17 & 85 & \\
\hline & & Total & 20 & 100 & \\
\hline & \multirow[t]{3}{*}{ Nurse } & Average & 2 & 6.7 & \\
\hline & & Excellent & 28 & 93.3 & \\
\hline & & Total & 30 & 100 & \\
\hline & \multirow[t]{3}{*}{ Nurse aid } & Average & 2 & 13.3 & \\
\hline & & Excellent & 13 & 86.7 & \\
\hline & & Total & 15 & 100 & \\
\hline & \multirow[t]{3}{*}{ Medical student } & Average & 2 & 13.3 & \\
\hline & & Excellent & 13 & 86.7 & \\
\hline & & Total & 15 & 100 & \\
\hline \multirow[t]{11}{*}{ Area of patients' rights } & \multirow[t]{3}{*}{ Physician } & Good & 3 & 16.7 & \multirow[t]{11}{*}{0.098} \\
\hline & & Excellent & 15 & 83.3 & \\
\hline & & Total & 18 & 100 & \\
\hline & Nurse & Good & 8 & 26.7 & \\
\hline & & Excellent & 22 & 73.3 & \\
\hline & & Total & 30 & 100 & \\
\hline & Nurse aid & Excellent & 14 & 100 & \\
\hline & & Total & 14 & 100 & \\
\hline & Medical student & Good & 1 & 6.7 & \\
\hline & & Excellent & 14 & 93.3 & \\
\hline & & Total & 15 & 100 & \\
\hline
\end{tabular}




\subsubsection{Appropriate and adequate information provided for the patient}

Mean rate of appropriate and adequate information provided for the patient was $85.8 \pm 7.8$ (out of 100) among subjects (range: 69.2-100). In addition, appropriate and adequate information provided for the patient was excellent in $48.1 \%$ of subjects. Results of chi-square showed no significant difference among four groups in terms of this area (Table 2).

\subsubsection{Respecting freedom of choice and decision-making of the patients in receiving services}

Mean rate of respecting freedom of choice and decision-making of the patients in receiving services was $90.3 \pm 7.9$ (out of 100) among subjects (range: 75-100). In addition, freedom of choice and decision-making of the patients in receiving services was perfect among most subjects $(88.8 \%)$. Results of chi-square showed no significant difference among four groups in terms of this area $(\mathrm{p}=0.791)$ (Table 2$)$.

\subsubsection{Respecting patients' privacy and observing the principle of confidentiality}

Mean rate of respecting patients' privacy and observing the principle of confidentiality was $100 \pm 0.0$ (out of 100) among subjects. In addition, respecting patients' privacy and observing the principle of confidentiality was perfect in all subjects $(100 \%)$.

\subsection{Observance of Patients' Rights (Four Areas)}

Mean rate of observing patients' rights (four areas of 1. respecting patients' privacy and observing the principle of confidentiality, 2. respecting freedom of choice and decision-making of the patients in receiving services, 3. providing appropriate and adequate information for patients and 4. receiving optimal health care) was $92.4 \pm 4.8$ (out of 100) among subjects. In addition, the amount of observance of patients' rights by most subjects was excellent (84.4\%). Results of chi-square showed no significant differences among four groups in terms of this area $(\mathrm{p}=0.098)$. Pearson correlation coefficient showed that there is no significant relation between age of participants and observing patients' rights by medical staff $(84.4 \%)(\mathrm{r}=0.011, \mathrm{p}=0.927)$. Results of independent $\mathrm{t}$-test showed no significant relation between subjects' gender and amount of observing patients' rights $(\mathrm{p}=0.140)$. Results of Spearman correlation coefficient showed no significant relation between subjects' education and amount of observing patients' rights $(\mathrm{r}=-0.005, \mathrm{p}=0.963)$. Results of chi-square showed no significant difference between gender of subjects and the rate of observing patients' rights $(\mathrm{p}=0.360)$.

\section{Discussion}

This study was conducted with the aim of determining the rate of observing patients' rights and abiding by the Patients' Rights Charter by physicians, nurses, nurse aids, and medical students of educational hospitals related to Mashhad University of Medical Sciences. Results showed that the amount of observing patients' rights by most medical staffs is excellent. In addition, the highest knowledge of subjects was related to providing health services based on respecting patients' privacy and observing the principle of confidentiality. In this regard, results of study by Nekooye Moghaddam et al. in Kerman showed that knowledge about Patients' Rights Charter among 80.2\% of subjects was good and observance of Patients' Rights Charter in 52.6\% was optimal (18). In addition, the lowest observance of patients' rights in the study by Nekooye Moghaddam was related to the right to receive adequate and appropriate information, which complies with results of present study. This compliance is related to both mentioned research centers being educational, the difference in ownership of medical centers and different expectations of patients hospitalized in the private sector relative to customers of the public sector (19). Results of a study by Kuzu et al. in Turkey also showed that the observance of patients' rights is optimal and observance of patients' privacy was reported to be $68.1 \%$ (20). Results of this study also comply with results of our study, and its possible cause is implementing issued legislations and training medical staff in terms of patients' rights and elevating awareness of medical staff; since, results of previous studies show that educational interventions can increase medical staff knowledge of patients' rights (21-23). Lack of full observance of patients' rights is shown in several studies and observance of patients' rights from nurses' perspective is reported to be average in more than half of cases (24). In other studies, lack of observance of patients' rights has been between 53.2 and $67.74 \%$ from patients' points of view (25-26). Of major causes for physicians and nurses not observing patients' rights completely, result can be from their lack of knowledge and attitude towards this issue. In addition, it is worth nothing that in the study by Arab et al. $77 \%$ of administrators of private hospitals in Tehran had no satisfactory knowledge of patients' rights (23). Average score given to observance of patients' respect and privacy was $100+0.0$ and it accounted for the highest value among four aspects of Patients' Rights Charter. Results of the study by Keshtkaran demonstrate that only $22 \%$ of nursing staff have pointed to giving patients' permission to use their belongings and only $8 \%$ pointed to observance of respect and human dignity while calling the patients (16). On the other hand, various studies have shown lack of full observance of patients' rights in terms of respect and observing their privacy, according to patients $(21,27,28)$. 
Obviously, observing privacy is among the most fundamental rights of every human and it is essential and necessary. It is mentioned in the Patients' Rights Charter of Iran and it is a necessity to observe it in healthcare organizations (29-31). Observing privacy is essential to creating an effective connection between medical staff and patients (23) and maintaining patient comfort (33) and outcomes of violating it are considerable and unpleasant. Different studies have shown that the more this privacy is observed by health care providers, the more the patients' satisfaction and consequently, their cooperation with health professionals, and it obliges patients to give their important information to health care providers and follow their orders more attentively (34). In this study, the average score of respecting freedom of choice and decision-making of patients in receiving health services was $90.3 \pm 7.9$ among subjects. In the study by Rangraz Jeddi et al., the right to receive treatment respectfully, among other rights, was given the lowest score, which does not comply with the present study (25). Respecting patients' dignity is an effective step towards increasing patients' satisfaction of provided services by medical staff and it will bring about outcomes including optimal relations between patients and staffs, feeling of being valued and reduction in the length of hospital stays, reduction in expenses and an increase in staffs' incentive to provide better services. Medical staff need to understand this concept to a greater extent in order to respect and observe it as much as possible (35). In terms of the patients' right to access information related to their diseases, the average score was $85.8 \pm 7.8$. Findings of the study by Zulfikar et al. showed that $33 \%$ of patients had received no explanation of their disease diagnosis and $53 \%$ of patients had no information about their treatment and medical treatment procedures (36). Additionally, in the study by Baba Mohammadi, the average score of observing patients' right to access information related to their diseases was low (28). In terms of freedom of choice and decision-making by patients, the average score of observance was 90.3 \pm 7.9. Lack of full observance of freedom of choice and patients' decisionmaking especially to change to another physician and rejecting treatment is shown in various studies $(25,28,37)$. It is worth noting that in the study by Goodarzi et al. observing this right was reported in half of physicians and nurses, which shows a lack of full observance of this right by them (38). In this study, no significant difference was observed between career and amount of observing patients' rights ( $\mathrm{p}>0.05)$. In the study by Rangraz Jeddi, a lack of significant difference between physicians and nurses views on the Patients' Rights Charter was shown (25). However, in the study by Amiri et al., a significant difference was observed between physicians and nurse aids in terms of their knowledge about the Patients' Rights Charter; but no significant difference was observed in terms of the amount of physicians and paramedics' attitude towards this issue (39). No significant difference was observed between gender and observance of patients' rights according to participants $(\mathrm{p}>0.05)$. Various studies have shown the lack of relation between gender and physicians, and nurses' awareness and attitude towards this issue (25, 39) which comply with result of present study.

\section{Conclusions}

Results of this study show that observance of patients' rights is optimal according to physicians, healthcare staff and general staff; although the area of providing appropriate and adequate information requires promotion. Therefore, it is suggested to consider more stringent regulatory policies parallel with various training programs in order to strengthen observance of patients' rights by medical staff of hospitals. Obviously, the possibility to train staffs in terms of the Patients' Rights Charter should also be provided for patients to make them aware of their own rights and enable them to request it from the healthcare system. In addition, it is suggested to pay more attention to students' curriculum and include the Patients' Rights Charter and teach it theoretically and practically, and employ experienced professors for this course. In addition, it is suggested to conduct more studies on this issue and compare attitudes of providers and caregivers in order to create a clearer image of the status of observing patients' rights and practical solutions to maximize observance of patients' rights.

\section{Acknowledgments:}

Hereby, the Research Deputy of Mashhad University of Medical Sciences is appreciated for financially supporting this project.

\section{Conflict of Interest:}

There is no conflict of interest to be declared.

Authors' contributions:

All authors contributed to this project and article equally. All authors read and approved the final manuscript.

\section{References:}

1) Sedghiani E. Hospital Management. First Edition. Jahan Rayaneh: Tehran. 1998. 
2) Zareyi A. Moroore bakhshhayi az masoulyathaye hoghoghe bimar dar nezame salamat. Tehran: Ministry of Health and Medical Education. 2004.

3) Mohammadi E. Study of Knowledge and attitudes of nurses in comparison to legal patient's rights and nurse. Proceedings of the Nurse and the Law Conference. Ministry of Health and Medical Education, Tehran, Iran. 1998: 161.

4) Smeltzer SC, Bare B. Medical -surgical nursing. Philadelphia: Lippincott. 2000: 7-8.

5) Leenen HJJ. Patient's Rights. Journal of World Health. 1996.

6) Emami Razavi S, Ravagi H, Hidarpour P, Dastjerdi R, Rafie S, Sadat SM, et al. Ashenayi ba mabani Hakmiyate balini. Tehran: Tandis Pub. 2011.

7) Parsapoor AR, Bagheri AR, Larijani B. Manshore hoghooghe bimar dar Iran. Iranian Journal of Medical Ethics and History of Medicine. 2009; 3(suppl): 39-47.

8) Asefzadeh S, Morshedi H, Kalantari Z. Evaluation of practicing patients' rights and ethical compliance in health centers affiliated to Gazvin university of medical Sciences and providing appropriate interventional solutions. Proceedings of the International Congress of Bioethics. 2005; 26-8.

9) Rangraz Jedi F, Rabiee R. A study on the attitude of physicians and nurses of Kashan Hospitals about the charter of patients' right, 2003. Fayz. 2006; 10(3): 40-6.

10) Shiraz B, Shamim MS, Shamim MS, Ahmed A. Medical ethics in surgical wards: Knowledge, attitude and practice of surgical team members in Karachi. Indian J Med Ethics. 2005; 2(3): 94-6. PMID: 16276659.

11) Basiri Moghadam K, Basiri Moghadam M, Moslem AR, Ajam Zibad H, Jamal F. Health Providers and Patients' Awareness on Patient Bill of Rights and Its Observing Rate in an Educational Hospital in Gonabad. Ofogh-e-Danesh. 2011; 17(2(51)): 45-55.

12) Vaskooei Eshkevari K, Karimi M, Asnaashari H, Kohan N. The assessment of observing patients' right in Tehran University of Medical Sciences' hospitals. Iranian Journal of Ethics and History of Medicine. 2009; 4(2): 47-54.

13) Rangraz Jedi F, Rabiy R. Mizane reayate manshore hoghooghe bimar dar bimarestanhay dolati Kashan. Behbood. 2005; 1(9): 62-71.

14) Malekshahi F. Level of practicing patients' rights by providers from patients' perspective in Korramabaad Shohada Hospital. Proceedings of the 2th International Congress of Medical Ethic; 2007: Ethics and History of Medicine Research Center, Tehran University of Medical Sciences. Tehran, Iran.

15) Abbasi A, Ziyaie A. Practicing patients' rights in hospitals: Mandatory for clinical governance implementation. Abstract book of first regional congress of clinical governance. 2010; Golestan University of Medical Sciences. Gorgan, Iran.

16) Hojjatoleslami S, Ghodsi Z. Respect the rights of patient in terms of hospitalized clients: a cross-sectional survey in Iran, 2010. Procedia-Soc Behav Sci. 2012; 31: 464-7. doi: 10.1016/j.sbspro.2011.12.087.

17) Nekoei Moghaddam M, Amiresmaeili MR, Ghobaninia R, Sharifi T, Tabatabaie S. Awarness of patients' rights charter and respecting it from the perspective of patients and nurses: a study of limited surgical centers in kerman city 2013. Bio right. 2014; 4(11): 31-56.

18) Rahmani A, Ghahramanian A, Mohajjalaghdam AR, Allahbakhshian A. Perception of patients regarding respecting to their autonomy during nursing care in hospitals affiliated to Tabriz University of Medical Sciences. Iranian journal of nursing research. 2008; 3(8-9): 7-14. PMID: 21589744.

19) Kuzu N, Ergin A, Zencir M. Patients' awareness of their rights in a developing country. Public Health. 2006; 120(4): 290-6. doi: 10.1016/j.puhe.2005.10.014. PMID: 16476454.

20) Hakan Ozdemir M, Ozgür Can I, Ergönen AT, Hilal A, Onder M, Meral D. Midwives and nurses awareness of patients' right. Midwifery. 2009; 25(6): 756-65. doi: 10.1016/j.midw.2008.01.010. PMID: 18346826.

21) Nasiriani KH, Farnia F, Nasirinia F. Study of respecting patients right from nurses' point of view employed in Yazd hospitals. Scientific journal of Forensic medicine. 2007; 13(1): 33-7.

22) Arab M, Zarei A. Patient rights: knowledge of managers of private hospitals. Payesh. 2009; 8(1): 25-30.

23) Rangraz Jedi F, Rabiei R. Patients' bill of rights in Kashan governmental hospitals, 2003. Behbood. 2005; 9(1): 62-71.

24) Ghasemi R. Status of respect to patient privacy and rights from patients view in Sabzevar city hospitals. Proceeding of The fisrt National Conference of Patient Right bill; Fasa: Fasa University of Medical Sciences. 2003; 60.

25) Babamahmoodi F, Meftahi M, Khdemloo M, Hesamzadeh A. A Study of patient rights implementation from patients view points in the educational hospitals of Mazandaran University of Medical Sciences. Iranian J Med Ethics Hist Med. 2011; 4(4): 37-44. 
26) Back E, Wikblad K. Privacy in hospital. J Adv Nurse. 1998; 27(5): 940-5. doi: 10.1046/j.13652648.1998.t01-1-00576.x. PMID: 9637320.

27) Low LP, Lee DT, Chan AwY. An exploratory study of Chinese older people's perceptions of privacy in residential care homes. J Adv Nurs. 2007; 57(6): 605-61. doi: 10.1111/j.1365-2648.2006.04116.x. PMID: 17346319.

28) Ohno-Machado L, Silveira PS, Vinterbo S. Protecting patient privacy by quantifiable control of disclosures in disseminated databases. Int J Med Inform. 2004; 73(7-8): 599-606. doi: 10.1016/j.ijmedinf.2004.05.002. PMID: 15246040.

29) Larkin GL, Moskop J, Sanders A, Derse A. The emergency physician and patient confidentiality: a review. Ann Emerg Med. 1994; 24(6): 1161-7. doi: 10.1016/S0196-0644(94)70249-7. PMID: 7978601.

30) Yura H, Walsh MB. Human needs 2 and the nursing process. New York: Appleton century crofts CO; 1983.

31) Hudak PL, Wright JG. The characteristics of Patient Satisfaction Measures. Spine (Phila Pa 1976). 2000; 25(24): 3168-77. doi: 10.1097/00007632-200012150-00012. PMID: 11124733.

32) Sadeghi T, Dehghan Nayyeri N. Patient's Dignity: A litrature review. Iranian J Med Ethics Hist Med. 2009; 3(1): 9-19.

33) Zulfikar F, Ulusoy MF. Are patients aware of their rights? A Turkish study. Nurs Ethics. 2001; 8(6): 48798. doi: 10.1177/096973300100800603. PMID: 16004104.

34) Hosnian M. A study of nurses' attitude about implementation clients right in hospital wards of Hamedan University of Medical Sciences. Proceeding of The fisrt National Conference of Patient Right bill. Fasa: Fasa University of Medical Sciences. 2003; 26-7.

35) Ghoodarzi MR, Rahnama M. A study of Patient rights implementation by physicians and nurses in Amiralmomenin hospital of Zabol City. Proceeding of The fisrt National Conference of Patient Right bill; Fasa University of Medical Sciences. 2003; 67.

36) Amiri M, Sadeghi E, Nazemi S. Doctors' and Paramedical Personnel's Level of knowledge and Attitude about Patients' Prism Ethics in Medical University of Shahrood Hospitals in year 2006. J Med Sci Mashhad Islamic Azad Uni. 2007; 3(3): 151-7. 